\title{
A RESERVA DO POSSÍVEL
}

Lucas Daniel Ferreira Souza

ISSUE DOI: $10.21207 / 1983.4225 .231$

\section{RESUMO}

O presente trabalho tem como foco as formas possíveis de se responsabilizar o Estado frente aos particulares e, por outro lado, as teses de defesa utilizadas pelo ente estatal quando comprovadamente impossível realizar a prestação pleiteada. Dessa forma, abordamos a Reserva do Possível, ou seja, a limitação orçamentária do Estado, quando confrontada com o Mínimo Existencial de cada direito fundamental social necessário para a existência humana digna. Por fim, discorreremos sobre a atuação do Poder Judiciário, bem como do Ministério Público e da Defensoria Pública, para coagir a Administração Pública a cumprir as medidas necessárias, assim como proteger e representar os indivíduos que estejam sofrendo restrições em seus direitos.

Palavras-Chave: Estado. Reserva do Possível. Poder Judiciário.

\section{INTRODUÇÃO}

A Reserva do Possível surgiu em julgamento promovido pelo Tribunal Constitucional Alemão, em decisão conhecida como Numerus Clausus (número restrito). 
Nesse caso, o Tribunal Constitucional analisou demanda judicial proposta por estudantes que não haviam sido admitidos nas escolas de Medicina de Hamburgo e Munique, em face da limitação do número de vagas em cursos superiores adotada pelo país em 1960, com fundamento no artigo 12 da Lei Fundamental alemã, que garantia a livre escolha de trabalho, ofício ou profissão.

Ao decidir a questão, a Corte alemã entendeu que o direito pleiteado, qual seja, o aumento do número de vagas na universidade, encontra limitação na Reserva do Possível, conceituada como o que o indivíduo pode razoavelmente exigir da sociedade, sob pena de, em virtude das limitações de ordem econômica, comprometer a plena efetivação dos direitos sociais.

Assim, a decisão foi que não seria razoável obrigar o Estado a disponibilizar o acesso a todos que pretendessem cursar medicina, eis que essa exigência estaria acima de um limite social básico.

Analisando a questão, Sarlet leciona que o Tribunal alemão entendeu que:

(...) a prestação reclamada deve corresponder ao que o indivíduo pode razoavelmente exigir da sociedade, de tal sorte que, mesmo em dispondo o estado de recursos e tendo poder de disposição, não se pode falar em uma obrigação de prestar algo que não se mantenha nos limites do razoável. ${ }^{1}$

Destaca-se que, mesmo que o Estado possua os recursos necessários disponíveis, não é obrigado a prestar algo que não seja razoável, como entendeu a Corte alemã no caso supracitado, referente aos estudantes que pleiteavam vagas de medicina em uma determinada instituição de ensino.

Desta forma, a Reserva do Possível, em sua origem, não leva em consideração única e exclusivamente a existência de recursos materiais suficientes para a efetivação do direito social, mas sim a razoabilidade da pretensão deduzida.

\footnotetext{
${ }^{1}$ SARLET, Ingo Wolfgang. A eficácia dos direitos fundamentais. 2 ed. Porto Alegre: Livraria do Advogado, 2001. p. 265.
} 
Em conclusão, a Reserva do Possível, quando de seu surgimento, estava relacionada intimamente com o limite da razoabilidade da prestação e não com a escassez de recursos, como veremos a seguir, que ocorre no Brasil.

\section{CONCEITO}

A Reserva do Possível é um elemento externo, capaz de limitar ou até restringir o acesso dos titulares a um direito fundamental social específico, face à limitação orçamentária do Estado.

No entendimento de Moraes, os direitos sociais:

(...) são direitos fundamentais do homem, caracterizando-se como verdadeiras liberdades positivas, de observância obrigatória em um Estado Social de Direito, tendo por finalidade a melhoria de condições de vida aos hipossuficientes, visando à concretização da igualdade social, e são consagrados como fundamentos do Estado Democrático, pelo art. $1^{\circ}$, IV, da Constituição Federal. ${ }^{2}$

No mesmo sentido, ensina Krell:

As normas programáticas sobre direitos sociais que hoje encontramos nas grandes maiorias dos textos constitucionais dos países europeus e latinoamericanos definem metas e finalidades, as quais o legislador ordinário deve elevar a um nível adequado de concretização. Essas "normas-programa" prescrevem a realização, por parte do Estado, de determinados fins e tarefas. Elas não representam meras recomendações ou preceitos morais com

2 MORAES, Alexandre de. Direito Constitucional Administrativo. 4 ed. São Paulo: Atlas, 2007. p. 177. 
eficácia ético-política meramente diretiva, mas constituem Direito diretamente aplicável. ${ }^{3}$

Os direitos fundamentais sociais do homem são aqueles garantidos constitucionalmente, fornecidos através de prestações do Estado, que visam garantir uma condição de vida digna a todos os membros da coletividade.

Dessa forma, deve-se fazer uma análise entre as possibilidades do ente público e a urgência da pretensão pleiteada, sob pena de, se manejada a situação de forma incorreta, causar grave lesão à economia pública ou ferir direitos garantidos constitucionalmente que consagram a dignidade da pessoa humana.

A Reserva do Possível, então, é invocada quando da impossibilidade de o Estado, através de prestações positivas, garantir plenamente a efetivação de todos os direitos fundamentais sociais, sob pena de grave prejuízo ao erário e, consequentemente, à sociedade como um todo.

\section{APLICABILIDADE NA REALIDADE BRASILEIRA}

A teoria da Reserva do Possível foi "importada" para o Brasil e interpretada unicamente como a Reserva do Financeiramente Possível, eis que é considerada como limite à concretização dos direitos fundamentais sociais tão somente a existência ou não de recursos públicos disponíveis.

Não é de se espantar que houve uma mudança na essência da teoria quando interpretada em solo pátrio, uma vez que existem significantes diferenças sociais, culturais e econômicas entre a Alemanha, berço da teoria da Reserva do Possível, e o Brasil.

Sobre a importação da Reserva do Possível pelo Brasil, face às grandes diferenças entre os países, critica Krell:

Devemos nos lembrar que os integrantes do sistema jurídico alemão não desenvolveram seus posicionamentos para com os direitos sociais num

\footnotetext{
${ }^{3}$ KRELL, Andreas J. Direitos Sociais e Controle Judicial no Brasil e na Alemanha: os descaminhos de um direito constitucional "comparado". Porto Alegre: Sergio Antônio Fabris Editor, 2002. p. 20.
} 
Estado de permanente crise social e milhões de cidadãos socialmente excluídos. Na Alemanha como nos países centrais - não há um grande contingente de pessoas que não acham vagas nos hospitais mal equipados da rede pública; não há necessidade de organizar a produção e distribuição da alimentação básica a milhões de indivíduos para evitar sua subnutrição ou morte; não há altos números de crianças e jovens fora da escola; não há pessoas que não conseguem sobreviver fisicamente com o montante pecuniário de assistência social que recebem, etc. ${ }^{4}$

Desse modo, no Brasil, em razão de sua realidade econômica e social, essa teoria é utilizada como óbice à efetivação dos direitos fundamentais sociais face à limitação do Estado em dispor de recursos financeiros suficientes para implementá-los.

A Reserva do Possível consiste na realização dos direitos sociais condicionada à quantidade de recursos disponíveis, sob pena de, ao dar enfoque a apenas um desses direitos, inviabilizar a prestação de outros.

Sobre o tema, assim se posiciona Barcellos:

(...) é importante lembrar que há um limite de possibilidades materiais para esses direitos. Em suma: pouco adiantará, do ponto de vista prático, a previsão normativa ou a refinada técnica hermenêutica se absolutamente não houver dinheiro para custear a despesa gerada por determinado direito subjetivo. ${ }^{5}$

Em virtude da ausência de condições financeiras de garantir integralmente todos os direitos fundamentais sociais, cabe ao Estado fazer

\footnotetext{
${ }^{4}$ KRELL, Andreas J. Direitos Sociais e Controle Judicial no Brasil e na Alemanha: os descaminhos de um direito constitucional "comparado". p.108.

5 BARCELlOS, Ana Paula de. A eficácia Jurídica dos Princípios Constitucionais. Rio de Janeiro: Renovar, 2002. p. 232.
} 
escolhas, estabelecendo as prioridades e critérios a serem seguidos, por meio da implementação de políticas públicas.

Nas palavras de Oliveira:

As políticas públicas são providências para que os direitos se realizem, para que as satisfações sejam atendidas, para que as determinações constitucionais e legais saiam do papel e se transformem em utilidades aos governados. ${ }^{6}$

As políticas públicas, que consistem na destinação do orçamento público para determinados fins, entretanto, encontram barreira na Reserva do Possível, face à limitação financeira do Estado.

Assim, cabe à Administração Pública, tendo em vista o caso concreto e os direitos conflitantes, buscar compatibilizá-los, procedendo a uma análise interpretativa que leva em conta a hierarquização desses direitos, fazendo prevalecer, dessa forma, os direitos considerados de maior relevância naquele determinado momento.

Este poder de escolha do Estado é denominado poder discricionário, por meio do qual a Administração Pública tem a liberdade de escolher, consultando a oportunidade e conveniência, a medida que mais convenha ao interesse público, sem necessidade de previsão legal.

Na lição de Meirelles:

Essa liberdade funda-se na consideração de que só o administrador, em contato com a realidade, está em condições de bem apreciar os motivos ocorrentes de oportunidade e conveniência da prática de certos atos, que seria impossível ao legislador, dispondo na regra jurídica - lei - de maneira geral e abstrata, prover com justiça e acerto. ${ }^{7}$

\footnotetext{
${ }^{6}$ OLIVEIRA, Régis Fernandes de. Curso de Direito Financeiro. São Paulo: Revista dos Tribunais, 2006. p. 251.

${ }^{7}$ MEIRELLES, Hely Lopes. Direito Administrativo Brasileiro. 29 ed. São Paulo: Malheiros Editores, 2004. p. 120.
} 
Obviamente, mesmo dispondo dessa liberdade, as escolhas realizadas pelo Estado devem ser pautadas pela Constituição Federal, que determina as diretrizes a serem seguidas a fim de satisfazer os objetivos fundamentais nela previstos.

Nessa esteira, assim leciona Canotilho:

$\mathrm{O}$ entendimento dos direitos sociais econômicos e culturais como direitos originários implica, como já foi salientado, uma mudança na função dos direitos fundamentais e põe como acuidade o problema de sua efectivação. Não obstante se falar aqui da efectivação dentro de uma 'reserva possível', para significar a dependência dos direitos econômicos, sociais e culturais dos 'recursos econômicos' a efetivação dos direitos econômicos sociais e culturais não se reduz a um simples 'apelo' ao legislador. Existe uma verdadeira imposição constitucional, legitimadora, entre outras coisas, de transformações econômicas e sociais na medida em que estas forem necessárias para efetivação desses direitos. $^{8}$

Vale salientar, então, que a discricionariedade nas condutas do administrador não permite que ele opte por concretizar ou não um direito fundamental, mas sim que, ao realizar a distribuição de recursos, faça uma ponderação no tocante aos bens jurídicos em questão.

Condicionar a efetivação dos direitos fundamentais sociais unicamente à existência ou não de recursos disponíveis e, consequentemente, à decisão do administrador, causa uma grande insegurança jurídica, razão pela qual as escolhas realizadas por esse devem ser sempre precedidas de uma análise cautelosa do caso concreto, visando sempre a melhor decisão possível para o conflito de interesses.

A Reserva do Possível, sob pena de ser utilizada pelo Estado como forma de se exonerar dolosamente do cumprimento de suas obrigações delineadas constitucionalmente, só poderá ser invocada quando res-

\footnotetext{
${ }^{8}$ CANOTILHO, José Joaquim Gomes. Direito constitucional e teoria da constituição. 3 ed. Coimbra: Almedina, 1999. p. 448.
} 
tar objetivamente comprovada a inexistência de recursos financeiros para a realização de determinado fim.

Assim, tendo em vista a vital importância da concretização dos direitos fundamentais sociais, a Reserva do Possível deve ser rechaçada quando invocada com o intuito de afastar a obrigatoriedade de efetivação dos referidos direitos pelo Estado, razão pela qual a mera alegação de insuficiência de recursos não é suficiente, devendo haver a clara comprovação da mesma.

Entretanto, o que se constata na realidade pátria é um completo descaso com a efetivação dos direitos sociais, notado pelo mau planejamento das verbas pelo Estado, conjuntamente com a criação de políticas públicas insuficientes para atender à demanda da população brasileira.

Questão que merece destaque neste sentido é a corrupção crescente em nosso país, o que vem comprometer a manutenção da qualidade de vida da população, eis que o interesse maior do administrador público, que deveria ser o bem comum, passa a ser interesse de cunho pessoal.

Sobre o caos político vivido hodiernamente em nosso país, posiciona-se Cambi:

Confiar unicamente, na concretização do interesse público, por parte dos administradores públicos, eleitos para isto, é fechar os olhos para a realidade brasileira marcada por inúmeros políticos despreparados, oportunistas, corruptos ou que fazem uso inadequado do dinheiro público. ${ }^{9}$

Nessa esteira, a corrupção viola diretamente os direitos fundamentais sociais da pessoa humana, ou seja, das prestações sociais obrigatórias por parte do Estado, como representante maior da sociedade.

Esses desvios de interesses, bem como a ausência de recursos financeiros, no entanto, não podem ter o condão de comprometer o mínimo necessário para a existência digna da pessoa humana, conforme passaremos a analisar.

${ }^{9}$ CAMBI, Eduardo. Neoconstitucionalismo e neoprocessualismo: Direitos fundamentais, políticas públicas e protagonismo judiciário. São Paulo: Revista dos Tribunais, 2009. p. 245. 


\section{RESERVA DO POSSÍVEL E O MÍNIMO EXISTENCIAL: EMBATE ENTRE DIREITOS FUNDAMENTAIS E LIMITA- ÇÕES ORÇAMENTÁRIAS}

A grande maioria dos direitos fundamentais depende de prestações positivas, exigindo gastos financeiros por parte do Estado, que encontra restrições para a total efetivação desses direitos na escassez de recursos.

Entretanto, não é possível deixar à mercê do Estado a decisão de implementar ou não ao menos uma parcela mínima de cada direito fundamental social necessária para garantir a vida digna de cada indivíduo, sob pena de atentar diretamente contra os direitos e garantias constitucionais.

Esta parcela mínima dos direitos fundamentais é chamada Mínimo Existencial, que, no entendimento de Rocha foi criado "[...] para dar efetividade ao princípio da possibilidade digna, ou da dignidade da pessoa humana possível, a ser garantido pela sociedade e pelo Estado". ${ }^{10}$

Acerca do núcleo abrangido pelo Mínimo Existencial, Canotilho expõe:

Das várias normas sociais, econômicas e culturais é possível deduzir-se um princípio jurídico estruturante de toda a ordem econômico-social portuguesa: todos (princípio da universalidade) têm um direito fundamental a um núcleo básico de direitos sociais (minimum core of economic and social rights) na ausência do qual o estado português deve se considerar infractor das obrigações jurídicosociais constitucional e internacionalmente impostas. ${ }^{11}$

Nesse diapasão, o Mínimo Existencial é o direito de cada indivíduo às condições mínimas indispensáveis para a existência humana

\footnotetext{
${ }^{10}$ ROCHA, Carmen Lúcia Antunes. O mínimo existencial e o princípio da reserva do possível. Belo Horizonte: Del Rey, 2005. p. 445.

11 CANOTILHO, José Joaquim Gomes. Direito Constitucional e Teoria da Constituição. 4 ed. Coimbra: Almedina, 2001. p. 203.
} 
digna, que não pode ser objeto de intervenção do Estado, mas que exige prestações positivas deste. Consiste, então, em um padrão mínimo de efetivação dos direitos fundamentais sociais pelo Estado.

Embora não esteja expressamente contido em nossa Constituição Federal, deve-se contextualizá-lo nos direitos humanos, na ideia de liberdade em todos os seus sentidos e nos princípios da igualdade e, acima de tudo, da dignidade da pessoa humana, princípio basilar das garantias constitucionais.

Sarlet conceitua a dignidade da pessoa humana da seguinte forma:

Temos por dignidade da pessoa humana a qualidade intrínseca e distintiva de cada ser humano que o faz merecedor do mesmo respeito e consideração por parte do Estado e da comunidade, implicando, neste sentido, um complexo de direitos e deveres fundamentais que assegurem a pessoa tanto contra todo $\mathrm{e}$ qualquer ato de cunho degradante $\mathrm{e}$ desumano, como venham a lhe garantir as condições existenciais mínimas para uma vida saudável, além de propiciar e promover sua participação ativa coresponsável nos destinos da própria existência e da vida em comunhão dos demais seres humanos. ${ }^{12}$

Nesse sentido, a existência humana digna não é considerada apenas no aspecto físico, no sentido de manutenção e sobrevivência do corpo, mas também no aspecto intelectual e espiritual, assegurando dentre outros os direitos à educação, alimentação e saúde.

Assim, é necessário que se reconheça certos direitos subjetivos a prestações ligados ao mínimo necessário para a existência digna do indivíduo, e não somente para sua subsistência. Sem a garantia desse mínimo imprescindível para a existência humana, há uma afronta direta ao direito constitucional à vida e, mais que isso, a uma vida com dignidade, base de todos os direitos fundamentais e humanos.

Não é possível, no entanto, elencar taxativamente os elementos que compõem o mínimo existencial de cada direito, sendo necessária uma

${ }^{12}$ SARLET, Ingo Wolfgang. A eficácia dos direitos fundamentais. p. 60. 
análise cautelosa do caso em concreto e do direito fundamental em questão.

A restrição de direitos fundamentais sociais somente se justifica quando não viola o Mínimo Existencial, ou seja, o núcleo essencial desses direitos. Mesmo existindo a limitação orçamentária do Estado, não cabe à Administração, por meio do poder discricionário, fazer escolhas no tocante a concretizar ou não o mínimo existencial de determinado direito fundamental, uma vez que esses são considerados pilares da existência humana digna, razão pela qual não podem ser olvidados.

Vale destacar que o objetivo maior do Estado é sempre concretizar integralmente os direitos fundamentais sociais, pois esses são indispensáveis para a vida humana digna. Não sendo possível, em razão de ausência de recursos, invocando-se neste caso a Reserva do Possível, pelo menos o Mínimo Existencial de cada um desses direitos dever ser garantido, porque possui prioridade nas destinações orçamentárias.

Assim é o entendimento de Barcellos:

Ao apurar os elementos fundamentais dessa dignidade (o mínimo existencial), estar-se-ão estabelecendo exatamente os alvos prioritários dos gastos públicos. Apenas depois de atingi-los é que se poderá discutir, relativamente aos recursos remanescentes, em que outros projetos se deverá investir. O mínimo existencial, como se vê, associado ao estabelecimento de prioridades orçamentárias é capaz de conviver produtivamente com a reserva do possível. ${ }^{13}$

Em síntese, a Reserva do Possível pode conviver pacificamente com o Mínimo Existencial, pois esse atua como um limite para a invocação daquela, ou seja, a Reserva do Possível só poderá ser invocada quando realizado o juízo da proporcionalidade e da garantia do Mínimo Existencial com relação a todos os direitos em questão.

Por derradeiro, o Mínimo Existencial surgiu para proteção dos indivíduos por meio da efetivação de uma parcela das garantias constitu-

13 BARCELlos, Ana Paula de. A eficácia Jurídica dos Princípios Constitucionais. p. 246. 
cionais aptas a proporcionar ao ser humano uma vida com dignidade, frente a todo o descaso que presenciamos diariamente do poder público para com as necessidades mais urgentes dos cidadãos.

No caso de haver qualquer desrespeito no tocante à concretização ao menos do núcleo essencial de determinado direito fundamental social, o Poder Judiciário deve ser acionado para intervir, pois, pelo caráter de indispensabilidade dos referidos direitos, eles gozam de proteção jurisdicional, conforme passaremos a tratar.

\section{$4 \quad$ ATUAÇÃO DO JUDICIÁRIO}

A limitada disponibilidade de recursos do Poder Público para prover as ilimitadas necessidades da coletividade é uma realidade que tem o condão de causar a insatisfação dos indivíduos que, comumente, acabam procurando o Poder Judiciário para a resolução do impasse.

No tocante à atuação do Poder Judiciário em temas referentes às políticas públicas, para aqueles que defendem não ser essa cabível, fala-se que a referida matéria está ligada à discricionariedade e conveniência do Poder Executivo, não podendo, portanto, ser objeto de pleito judicial, sob pena de desrespeitar o princípio da Separação dos Poderes.

De acordo com esse entendimento, é atribuição exclusiva do poder estatal decidir de que forma e onde os recursos públicos devem ser aplicados.

A Constituição Federal de 1988 passa a assegurar, de forma expressa, a proteção de direitos, sejam eles privados, públicos ou transindividuais (difusos, coletivos ou individuais homogêneos).

Destarte, traz expressamente em seu artigo $5^{\circ}$, inciso XXXV, a possibilidade de se recorrer às vias judiciais quando da violação de direitos: "A lei não excluirá da apreciação do poder judiciário lesão ou ameaça de lesão a direito".

De acordo com os ensinamentos de Lenza, "o artigo $5^{\circ}$, inciso XXXV veio sedimentar o entendimento amplo do termo direito, dizendo 
que a lei não excluirá da apreciação do Poder Judiciário lesão ou ameaça a direito, não mais restringindo a sua amplitude." 14

O desrespeito aos princípios e garantias fundamentais indispensáveis para a existência humana já fundamenta a intervenção do Poder Judiciário que deverá agir não de forma ilimitada, mas analisando sempre a situação concreta.

Ao encontro desse posicionamento, Barcellos afirma:

(...) nem a separação de poderes nem o princípio majoritário são absolutos em si mesmos, sendo possível excepcioná-los em determinadas hipóteses, especialmente quando se tratar de garantia dos direitos fundamentais e da dignidade da pessoa humana. ${ }^{15}$

Não está havendo, portanto, usurpação das funções de um poder sobre o outro nem tampouco invasão na seara administrativa, eis que é papel do Judiciário agir diante de violação de direito subjetivo constitucional, corrigindo eventuais distorções provocadas pela Administração Pública.

Atuando desta forma, não se atribui ao Judiciário o poder de criar políticas públicas, mas sim o de obrigar que sejam executadas aquelas que já são objeto de legislação.

O Ministro Encinas Manfré, do Tribunal de Justiça do Estado de São Paulo, assim se manifestou no julgamento da Apelação no ${ }^{\circ}$ 915288905.2008.8.26.0000:

Inocorrência de violação ao princípio da separação dos poderes. Cabível determinação judicial para que assegurados direitos fundamentais de crianças e adolescentes, os quais disciplinados na Constituição da República, em Convenção Internacional incorporada ao ordenamento jurídico brasileiro,

\footnotetext{
14 LENZA, Pedro. Direito Constitucional Esquematizado. 13 ed. São Paulo: Saraiva, 2009. p. 698.

${ }^{15}$ BARCELlOS, Ana Paula de. A eficácia Jurídica dos Princípios Constitucionais. Rio de Janeiro: Renovar, 2002.. p. 230.
} 
assim como na Lei 8.060/1990. Possibilidade jurídica dos pedidos formulados pelo autor. Arguições preliminares rejeitadas.

No mesmo sentido, o Ministro Vicente de Abreu Amadei, do Tribunal de Justiça do Estado de São Paulo entendeu no julgamento da Apelação no 0006359-60.2010.8.26.0019:

APELAÇÃO - Ação ordinária de obrigação de fazer - Pessoa hipossuficiente, portadora de "tumor neuroendócrino" (carcinoma endócrino pouco diferenciado do corpo de pâncreas - CID C 25 - com metástases) Medicamento prescrito por médico (177LU Dota Try Octreotato Lutécio) Obrigação do Município -

Legitimidade passiva e solidariedade dos entes públicos - Direito fundamental ao fornecimento gratuito de medicamentos, insumos e ao custeio de tratamento - Aplicação dos arts. $1^{\circ}$, III, e $6^{\circ}$ da CF Princípios da isonomia, da tripartição de funções estatais e da discricionariedade da Administração não violados - Falta de padronização dos bens pretendidos, limitação orçamentária e teoria da reserva do possível - Teses afastadas - Cominação de multa, em obrigação imposta a ente público Viabilidade Honorários de advogado Valor excessivo para a natureza da ação Redução Apelação e Recurso de ofício parcialmente providos. Solidária a responsabilidade dos entes públicos (art. 196 da CF), há legitimidade passiva do demandado isoladamente ou em conjunto, ainda que não se inclua todos os entes responsáveis, observados o litisconsórcio facultativo (não necessário). Os princípios da dignidade da pessoa humana (art. $1^{\circ}$, III, da CF) e da preservação da saúde dos cidadãos em geral (art. $6^{\circ}$ da $\mathrm{CF}$ ) impõem ao Município a obrigação de fornecer, prontamente, medicamento e insumo necessitados, em favor de pessoa hipossuficiente, sob responsabilidade solidária dos entes públicos (art. 196 da CF). Havendo direito subjetivo fundamental violado, não há ofensa aos princípios da isonomia, da tripartição de funções 
estatais e da discricionariedade da Administração, e, no quadro da tutela do mínimo existencial, não se justifica inibição à efetividade do direito ofendido sob os escudos de falta de padronização ou de inclusão dos bens em lista oficial, de limitações orçamentárias e de aplicação da teoria da reserva do possível.

Logo, não há invasão do Judiciário na seara administrativa nesses casos, mas tão somente controle judicial acerca de descumprimento de preceito legal.

Os direitos previstos na legislação por si só são vazios quando não dotados de efetividade. Nesse diapasão, em virtude da prevalência dos direitos fundamentais, cabe ao Judiciário, como intérprete e aplicador do direito, assegurar efetividade às normas constitucionais, conforme dispõe o julgado a seguir:

E M E N T A: PACIENTE COM HIV/AIDS PESSOA DESTITUÍDA DE RECURSOS FINANCEIROS - DIREITO À VIDA E À SAÚDE FORNECIMENTO GRATUITO DE MEDICAMENTOS - $\quad$ DEVER CONSTITUCIONAL DO PODER PÚBLICO (CF, ARTS. 5', CAPUT, E 196) - PRECEDENTES (STF) - RECURSO DE AGRAVO IMPROVIDO. O DIREITO À SAÚDE REPRESENTA CONSEQUENNCIA CONSTITUCIONAL INDISSOCIÁVEL DO DIREITO À VIDA. - O direito público subjetivo à saúde representa prerrogativa jurídica indisponível assegurada à generalidade das pessoas pela própria Constituição da República (art. 196). Traduz bem jurídico constitucionalmente tutelado, por cuja integridade deve velar, de maneira responsável, o Poder Público, a quem incumbe formular - e implementar - políticas sociais e econômicas idôneas que visem a garantir, aos cidadãos, inclusive àqueles portadores do vírus HIV, o acesso universal e igualitário à assistência farmacêutica e médico-hospitalar. - $\mathrm{O}$ direito à saúde - além de qualificar-se como direito fundamental que assiste a todas as pessoas - representa consequência 
constitucional indissociável do direito à vida. $\mathrm{O}$ Poder Público, qualquer que seja a esfera institucional de sua atuação no plano da organização federativa brasileira, não pode mostrar-se indiferente ao problema da saúde da população, sob pena de incidir, ainda que por censurável omissão, em grave comportamento inconstitucional. A INTERPRETAÇÃO DA NORMA PROGRAMÁTICA NÃO PODE TRANSFORMÁLA EM PROMESSA CONSTITUCIONAL INCONSEQUENTE. - O caráter programático da regra inscrita no art. 196 da Carta Política - que tem por destinatários todos os entes políticos que compõem, no plano institucional, a organização federativa do Estado brasileiro - não pode converterse em promessa constitucional inconseqüente, sob pena de o Poder Público, fraudando justas expectativas nele depositadas pela coletividade, substituir, de maneira ilegítima, o cumprimento de seu impostergável dever, por um gesto irresponsável de infidelidade governamental ao que determina a própria Lei Fundamental do Estado. DISTRIBUIÇÃO GRATUITA DE MEDICAMENTOS A PESSOAS CARENTES. - O reconhecimento judicial da validade jurídica de programas de distribuição gratuita de medicamentos a pessoas carentes, inclusive àquelas portadoras do vírus HIV/AIDS, dá efetividade a preceitos fundamentais da Constituição da República (arts. $5^{\circ}$, caput, e 196) e representa, na concreção do seu alcance, um gesto reverente e solidário de apreço à vida e à saúde das pessoas, especialmente daquelas que nada têm e nada possuem, a não ser a consciência de sua própria humanidade e de sua essencial dignidade. Precedentes do STF. (STF - RE 271.286/RS, rel. Min. Celso de Mello, DJ 24/11/2000).

A jurisprudência brasileira é tranquila no sentido de preservar a efetividade do Mínimo Existencial, entendendo que, por se enquadrar nos direitos fundamentais sociais, não se expõe à avaliação discricionária da Administração Pública. 
O Poder Público utiliza como tese defensiva a Reserva do Possível, que não vem sendo aceita pelas decisões jurisprudenciais quando meramente alegada, exigindo-se a efetiva comprovação de ausência de recursos.

Nesse contexto, assim decidiu o Superior Tribunal Federal, rechaçando a alegação de insuficiência orçamentária:

CRECHE E PRÉ-ESCOLA - OBRIGAÇ̃̃O DO
ESTADO $\quad-\quad$ IMPOSIÇÃO
INCONSTITUCIONALIDADE VERIFICADA - RECURSO EXTRAORDINÁRIO NEGATIVA DE SEGUIMENTO. 1. Conforme preceitua o artigo 208, inciso IV, da Carta Federal, consubstancia dever do Estado a educação, garantindo o atendimento em creche e pré-escola às crianças de zero a seis anos de idade. O Estado União, Estados propriamente ditos, ou seja, unidades federadas, e Municípios - deve aparelhar-se para a observância irrestrita dos ditames constitucionais, não cabendo tergiversar mediante escusas relacionadas com a deficiência de caixa. Eis a enorme carga tributária suportada no Brasil a contrariar essa eterna lengalenga. $\mathrm{O}$ recurso não merece prosperar, lamentando-se a insistência do Município em ver preservada prática, a todos os títulos nefasta, de menosprezo àqueles que não têm como prover as despesas necessárias a uma vida em sociedade que se mostre consentânea com a natureza humana. 2. Pelas razões acima, nego seguimento a este extraordinário, ressaltando que o acórdão proferido pela Corte de origem limitou-se a ferir o tema à luz do artigo 208, inciso IV, da Constituição Federal, reportando-se, mais, a compromissos reiterados na Lei Orgânica do Município - artigo 247, inciso I, e no Estatuto da Criança e do Adolescente - artigo 54, inciso IV. 3. Publique-se. (STF, Decisão Monocrática, RE no 356.479-0, Rel. Min. Marco Aurélio. J. em 30/04/04, DJU em 24/05/04)

E M E N T A: RECURSO EXTRAORDINÁRIO CRIANÇA DE ATÉ SEIS ANOS DE IDADE ATENDIMENTO EM CRECHE E EM PRÉ- 
ESCOLA - EDUCAÇÃO INFANTIL DIREITO ASSEGURADO PELO PRÓPRIO TEXTO CONSTITUCIONAL (CF, ART. 208, IV) COMPREENSÃO GLOBAL DO DIREITO CONSTITUCIONAL À EDUCAÇÃO - DEVER JURÍDICO CUJA EXECUÇÃO SE IMPÕE AO PODER PÚBLICO, NOTADAMENTE AO MUNICÍPIO (CF, ART. 211, § $2^{\circ}$ ) - RECURSO IMPROVIDO.

- A educação infantil representa prerrogativa constitucional indisponível, que, deferida às crianças, a estas assegura, para efeito de seu desenvolvimento integral, e como primeira etapa do processo de educação básica, o atendimento em creche e o acesso à pré-escola (CF, art. 208, IV). Essa prerrogativa jurídica, em consequência, impõe, ao

Estado, por efeito da alta significação social de que se reveste a educação infantil, a obrigação constitucional de criar condições objetivas que possibilitem, de maneira concreta, em favor das "crianças de zero a seis anos de idade" (CF, art. 208, IV), o efetivo

acesso e atendimento em creches e unidades de préescola, sob pena de configurar-se inaceitável omissão governamental, apta a frustrar, injustamente, por inércia, o integral adimplemento, pelo Poder Público, de prestação estatal que lhe impôs o próprio texto da Constituição Federal.

- A educação infantil, por qualificar-se como direito fundamental de toda criança, não se expõe, em seu processo de concretização, a avaliações meramente discricionárias da Administração Pública, nem se subordina a razões de puro pragmatismo governamental.

- Os Municípios - que atuarão, prioritariamente, no ensino fundamental e na educação infantil $(\mathrm{CF}$, art. $\left.211, \S 2^{\circ}\right)$ - não poderão demitir-se do mandato constitucional, juridicamente vinculante, que lhes foi outorgado pelo art. 208, IV, da Lei Fundamental da República, e que representa fator de limitação da discricionariedade político-administrativa dos entes municipais, cujas opções, tratando-se do 
atendimento das crianças em creche (CF, art. 208, IV), não podem ser exercidas de modo a comprometer, com apoio em juízo de simples conveniência ou de mera oportunidade, a eficácia desse direito básico de índole social.

- Embora resida, primariamente, nos Poderes Legislativo e Executivo, a prerrogativa de formular e executar políticas públicas, revela-se possível, no entanto, ao Poder Judiciário, determinar, ainda que em bases excepcionais, especialmente nas hipóteses de políticas públicas definidas pela própria Constituição, sejam estas implementadas pelos órgãos estatais inadimplentes, cuja omissão - por importar em descumprimento dos encargos políticojurídicos que sobre eles incidem em caráter mandatório - mostra-se apta a comprometer a eficácia e a integridade de direitos sociais e culturais impregnados de estatura constitucional. A questão pertinente à "reserva do possível". (STF - RE 436996/SP, rel. Min. Celso de Mello, DJ 07/11/2005)

Como se percebe, o que tem acontecido constantemente é o Poder Público agir sem razoabilidade, com a clara intenção de neutralizar os direitos fundamentais sociais, afetando de forma direta, mediante inércia estatal ou abuso governamental, as condições mínimas imprescindíveis para uma existência humana digna.

Nesse sentido é a decisão proferida pelo Ministro Celso de Mello no julgamento da Arguição de Descumprimento de Preceito Fundamental $n^{\circ} 45$ :

É que a realização dos direitos econômicos, sociais e culturais - além de caracterizar-se pela gradualidade de seu processo de concretização - depende, em grande medida, de um inescapável vínculo financeiro subordinado às possibilidades orçamentárias do Estado, de tal modo que, comprovada, objetivamente, a incapacidade econômico-financeira da pessoa estatal, desta não se poderá razoavelmente exigir, considerada a limitação material referida, a imediata efetivação do 
comando fundado no texto da Carta Política. Não se mostrará lícito, no entanto, ao Poder Público, em tal hipótese - mediante indevida manipulação de sua atividade financeira e/ou político-administrativa criar obstáculo artificial que revele o ilegítimo, arbitrário e censurável propósito de fraudar, de frustrar e de inviabilizar o estabelecimento e a preservação, em favor da pessoa e dos cidadãos, de condições materiais mínimas de existência. Cumpre advertir, desse modo, que a cláusula da "reserva do possível" - ressalvada a ocorrência de justo motivo objetivamente aferível - não pode ser invocada, pelo Estado, com a finalidade de exonerar-se do cumprimento de suas obrigações constitucionais, notadamente quando, dessa conduta governamental negativa, puder resultar nulificação ou, até mesmo, aniquilação de direitos constitucionais impregnados de um sentido de essencial fundamentalidade.

Analisando a decisão supra, fica claro que alegar limitação orçamentária, invocando a Reserva do Possível, por si só, não tem o condão de justificar a omissão estatal, especialmente nos casos em que está em jogo a concretização do mínimo existencial de determinado direito fundamental social.

Muito embora a limitação orçamentária seja uma realidade, quando se trata do mínimo existencial de um direito fundamental e não houver real impossibilidade objetiva demonstrada, a omissão administrativa não encontra justificativa na Reserva do Possível.

Por outro lado, o que também não pode ocorrer é o Poder Judiciário, solícito aos pleitos dos indivíduos para obterem determinadas prestações judiciais, ordenar que as referidas prestações sejam executadas sem levar em consideração os fundamentos apresentados pela Administração Pública, que, naquele momento, pode se encontrar incapaz de atender os pleitos em questão.

Esse tipo de decisão do Judiciário, no qual não existe uma análise cautelosa do caso em concreto, pode resultar em sérios problemas para a Administração Pública, posto que o administrador, para conseguir cumprir o determinado nas decisões judiciais, muitas vezes tem que retirar recursos de uma área específica para que sejam aplicados conforme o ordenamento judicial. 
Essa situação acarreta uma violação direta ao princípio constitucional da igualdade, pois para cumprir determinada decisão judicial e, em consequência, beneficiar um indivíduo específico, muitas vezes o Poder Público, conforme já citado, precisa realocar verbas de outra área, causando prejuízo àqueles que dela dependiam.

Por derradeiro, o Poder Judiciário possui uma grande responsabilidade ao apurar os casos concretos, ponderando e decidindo sempre pelo caminho que priorize o bem comum.

\section{$5 \quad$ ATUAÇÃO DO MINISTÉRIO PÚBLICO}

É de conhecimento geral que é dever do Estado viabilizar o acesso efetivo às políticas públicas determinadas constitucionalmente. No entanto, não obstante a alegação de limitação orçamentária para a implementação de políticas públicas, cabe ao Ministério Público apurar se tal afirmação procede e, em caso negativo, comprovar objetivamente a capacidade orçamentária do Poder Público para exigir a efetivação do direito constitucional em questão.

Por expressa determinação constitucional, o ministério público é órgão defensor do interesse social, conforme o disposto no art. 129, II, da Constituição Federal:

Art. 129 - São funções institucionais do Ministério Público:

II - zelar pelo efetivo respeito dos Poderes Públicos e dos serviços de relevância pública aos direitos assegurados nesta Constituição, promovendo as medidas necessárias a sua garantia;

Sempre visando o interesse da coletividade, é de grande importância para o trabalho desenvolvido pelo Ministério Público o poder de realização do Inquérito Civil, instrumento investigativo exclusivo do referido órgão, bem como detém legitimidade para o ajuizamento de Ação Civil Pública, além de ter poderes para a realização de TAC - Termo de Ajustamento de Conduta.

O TAC é um instituto utilizado antes e com o fim de evitar que se venha a instaurar o processo judicial. É um instituto de caráter conci- 
liatório, adotado com o objetivo de composição e tutela de interesses metaindividuais, entre o Ministério Público e a parte interessada, de modo que essa se comprometa a agir da forma que for acordada.

O Ministério Público também é parte legítima e tem interesse de agir para propor ação civil pública, na qual defende interesses individuais indisponíveis, pois, neste molde, qualifica-se o direito à vida e à saúde.

No mesmo sentido, o Ministro Vicente de Abreu Amadei, do Tribunal de Justiça do Estado de São Paulo, julgou a Apelação $\mathrm{n}^{\mathbf{o}}$ 0004821-49.2010.8.26.0664:

APELAÇÃO - Ação Civil Pública - Pessoa hipossuficiente, e portadora de "Diabetes tipo 1" (CID 10: elO-0) - Medicamento prescrito por médico (Lantus Salustar e Apidra Salustar) Insumos necessário (agulhas BD de $5 \mathrm{~mm}$ ) Interesse de agir - Necessidade da jurisdição sem exaurir a via administrativa - Obrigação do Município - Legitimidade ativa do Ministério Público - Direito fundamental ao fornecimento gratuito de medicamentos e insumos

- Aplicação dos arts. I, III, e 6o da CF - Princípios da isonomia, da tripartição de funções estatais e da discricionariedade da Administração não violados Limitação orçamentária e teoria da reserva do possível - Teses afastadas - Cominação de multa, em obrigação imposta a ente público -Viabilidade Recurso não provido.

1. O Ministério Público tem legitimidade para o ajuizamento de ação civil pública destinada à tutela individual de direito fundamental indisponível (arts. 127 c.c. 129, III, ambos da CF), em favor de pessoa hipossuficiente, e essa legitimidade de raiz constitucional, para idoso, ainda conta com amparo legal (arts. 15, 74 e 79 do Estatuto do Idoso).

2. Os princípios da dignidade da pessoa humana (art. Io, III, da CF) e da preservação da saúde dos cidadãos em geral (art. 6o da CF) impõem ao Estado a obrigação de fornecer, prontamente, medicamento e insumo necessitados, em favor de pessoa hipossuficiente, sob responsabilidade solidária dos entes públicos (art. 196 da CF). 
3. Havendo direito subjetivo fundamental violado, não há ofensa aos princípios da isonomia, da tripartição de funções estatais e da discricionariedade da Administração, e, no quadro da tutela do mínimo existencial, não se justifica inibição à efetividade do direito ofendido sob os escudos de falta de padronização ou de inclusão dos bens em lista oficial, de limitações orçamentárias e de aplicação da teoria da reserva do possível.

4. É viável a cominação de multa, a título de astreinte, ao Poder Público, em obrigação que lhe é imposta por sentença.

No que tange à tutela jurisdicional dos direitos individuais homogêneos, decidiu o Supremo Tribunal Federal:

O Ministério Público tem legitimidade para ajuizar ação civil pública objetivando o fornecimento de remédio pelo Estado. Com base nesse entendimento, a Turma proveu recurso extraordinário em que se questionava a obrigatoriedade de o Estado proporcionar a certa cidadã medicamentos indispensáveis à preservação de sua vida. No caso, tribunal local extinguira o processo sem julgamento de mérito, ante a mencionada ilegitimidade ativa ad causam do parquet, uma vez que se buscava, por meio da ação, proteção a direito individual, no caso, de pessoa idosa (Lei 8.842/94, art. $2^{\circ}$ ). Sustentavase, na espécie, afronta aos artigos 127 e 129, II e III, da CF. Assentou-se que é função institucional do parquet zelar pelo efetivo respeito dos Poderes Públicos e dos serviços de relevância pública aos direitos assegurados na Constituição, promovendo medidas necessárias a sua garantia (CF, art. 129, II). (STF, RE 407902/RS, rel. Min. Marco Aurélio, 26.5.2009. (RE-407902).

E $\mathrm{M}$ E $\mathrm{N}$ T A: DIREITOS INDIVIDUAIS HOMOGÊNEOS - SEGURADOS DA PREVIDÊNCIA SOCIAL - CERTIDÃO PARCIAL DE TEMPO DE SERVIÇO - RECUSA DA AUTARQUIA 
PREVIDENCIÁRIA - DIREITO DE PETIÇÃO E DIREITO DE OBTENÇÃO DE CERTIDÃO EM REPARTIÇÕES PÚBLICAS - PRERROGATIVAS JURÍDICAS DE ÍNDOLE EMINENTEMENTE CONSTITUCIONAL - EXISTÊNCIA DE RELEVANTE INTERESSE SOCIAL - AÇÃO CIVIL PÚBLICA - LEGITIMAÇÃO ATIVA DO MINISTÉRIO PÚBLICO - A FUNÇÃO INSTITUCIONAL DO MINISTÉRIO PÚBLICO COMO "DEFENSOR DO POVO" (CF, ART, 129, II) - DOUTRINA - PRECEDENTES - RECURSO DE AGRAVO IMPROVIDO. - O direito à certidão traduz prerrogativa jurídica, de extração constitucional, destinada a viabilizar, em favor do indivíduo ou de uma determinada coletividade (como a dos segurados do sistema de previdência social), a defesa (individual ou coletiva) de direitos ou o esclarecimento de situações. - A injusta recusa estatal em fornecer certidões, não obstante presentes os pressupostos legitimadores dessa pretensão, autorizará a utilização de instrumentos processuais adequados, como o mandado de segurança ou a própria ação civil pública. - O Ministério Público tem legitimidade ativa para a defesa, em juízo, dos direitos e interesses individuais homogêneos, quando impregnados de relevante natureza social, como sucede com o direito de petição e o direito de obtenção de certidão em repartições públicas. Doutrina. Precedentes. (STF - RE 472489 AgR/RS, rel. Min. Celso de Mello, DJ 29/08/2008).

Desta forma, extrai-se dos entendimentos acima que a legitimidade do Ministério Público é inquestionável no que diz respeito à defesa dos direitos fundamentais sociais dos indivíduos, sejam eles metaindividuais ou individuais indisponíveis.

\section{ATUAÇÃO DA DEFENSORIA PÚBLICA}

A Defensoria Pública é uma instituição permanente e indispensável cuja atribuição é oferecer aos cidadãos hipossuficientes, de forma 
integral e gratuita, orientação jurídica e a defesa dos direitos individuais e coletivos.

Desta forma, cabe à Defensoria, em cada caso específico, objetivar a efetivação judicial do direito fundamental, de modo a concretizar o princípio constitucional da dignidade da pessoa humana.

É de vital importância destacar que a Lei $n^{\circ} 11.448$, de 15 de janeiro de 2007, alterando o art. $5^{\circ}$ da Lei $\mathrm{n}^{\circ} 7.347 / 85$, legitima a Defensoria Pública para propositura da ação civil pública.

A seguir, alguns julgados do Superior Tribunal de Justiça que tratam sobre o tema em questão:

"PROCESSUAL CIVIL. AÇÃO COLETIVA. DEFENSORIA PÚBLICA. LEGITIMIDADE ATIVA. ART. 5', II, DA LEI $\mathrm{N}^{\circ} 7.347 / 1985$ (REDAÇÃO DA LEI $\mathrm{N}^{\circ}$ 11.448/2007). PRECEDENTE.

1. Recursos especiais contra acórdão que entendeu pela legitimidade ativa da Defensoria Pública para propor ação civil coletiva de interesse coletivo dos consumidores.

2. Este Superior Tribunal de Justiça vem-se posicionando no sentido de que, nos termos do art. $5^{\circ}$,II, da Lei $n^{\circ} 7.347 / 85$ (com a redação dada pela Lei $\mathrm{n}^{\mathrm{o}}$ 11.448/07), a Defensoria Pública tem legitimidade para propor a ação principal e a ação cautelar em ações civis coletivas que buscam auferir responsabilidade por danos causados ao meioambiente, ao consumidor, a bens e direitos de valor artístico, estético, histórico, turístico e paisagístico e dá outras providências.

3. Recursos especiais não-providos." (Primeira Turma, REsp n. 912.849/RS, relator Ministro José Delgado, DJe de 28.4.2008.)

PROCESSUAL CIVIL. EMBARGOS DE DECLARAÇÃO. OMISSÃO NO JULGADO. INEXISTÊNCIA. AÇÃO CIVIL PÚBLICA. DEFESA COLETIVA DOS CONSUMIDORES. CONTRATOS DE ARRENDAMENTO MERCANTIL ATRELADOS A MOEDA ESTRANGEIRA. MAXIDESVALORIZAÇÃO DO 
REAL FRENTE AO DÓLAR NORTEAMERICANO. INTERESSES INDIVIDUAIS HOMOGÊNEOS. LEGITIMIDADE ATIVA DO ÓRGÃO ESPECIALIZADO VINCULADO À DEFENSORIA PÚBLICA DO ESTADO.

I - O NUDECON, órgão especializado, vinculado à Defensoria Pública do Estado do Rio de Janeiro, tem legitimidade ativa para propor ação civil pública objetivando a defesa dos interesses da coletividade de consumidores que assumiram contratos de arrendamento mercantil, para aquisição de veículos automotores, com cláusula de indexação monetária atrelada à variação cambial.

II - No que se refere à defesa dos interesses do consumidor por meio de ações coletivas, a intenção do legislador pátrio foi ampliar o campo da legitimação ativa, conforme se depreende do artigo 82 e incisos do CDC, bem assim do artigo $5^{\circ}$, inciso XXXII, da Constituição Federal, ao dispor, expressamente, que incumbe ao "Estado promover, na forma da lei, a defesa do consumidor".

III - Reconhecida a relevância social, ainda que se trate de direitos essencialmente individuais, vislumbra-se o interesse da sociedade na solução coletiva do litígio, seja como forma de atender às políticas judiciárias no sentido de se propiciar a defesa plena do consumidor, com a conseqüente facilitação ao acesso à Justiça, seja para garantir a segurança jurídica em tema de extrema relevância, evitando-se a existência de decisões conflitantes.

Recurso especial provido." (Terceira Turma, REsp n. 555.111/RJ, relator Ministro Castro Filho, DJ de 18/12/2006.)

Deste modo, depreende-se que a Defensoria Pública, além se sua função típica, qual seja representar judicial e extrajudicialmente os direitos dos necessitados, possui também a função de zelar pela concretização dos direitos fundamentais sociais necessários para garantir a existência digna do indivíduo. 


\section{CONSIDERAÇÕES FINAIS}

A ideia que se encontra encartada no conceito de "Reserva do Possível" não pode se constituir como uma escusa dos governos em cumprir com as políticas públicas que viabilizam a concretização dos direitos sociais na realidade fática.

Não se deve permitir, portanto, que o argumento da Reserva do Possível constitua um escudo que proteja o Estado de sua inatividade, considerando que esse tem negligenciado, por diversas vezes, direitos que, na verdade, não são impossíveis de serem concretizados, ou seja, que se enquadram perfeitamente no âmbito da reserva do possível.

A grande celeuma surge quando analisamos a Reserva do Possível no contexto do Mínimo Existencial. A Reserva do Possível, embora seja aceita em algumas hipóteses, não pode ser um óbice para a efetivação de pelo menos uma porção mínima de cada direito fundamental social, imprescindível a garantir a efetivação do princípio constitucional da dignidade da pessoa humana.

Portanto, não se despreza a aplicabilidade e razoabilidade da Reserva do Possível em determinadas situações. O que se defende é que esse princípio não seja usado de forma aleatória, com simples alegações. Portanto, há necessidade que o Poder Público demonstre, ou seja, prove que a negativa do oferecimento ao direito do indivíduo é para que não prejudique a efetivação de outros direitos ligados ao mínimo existencial da população.

Neste contexto, quando se tratar de garantia dos direitos fundamentais sociais, cabe ao Judiciário intervir em favor da realização destes, sem, no entanto, interferir na esfera de atuação da Administração Pública.

O Ministério Público e a Defensoria Pública, como defensores do interesse social, também possuem legitimidade para objetivar a efetivação judicial do direito fundamental lesado.

\section{REFERÊNCIAS BIBLIOGRÁFICAS}

BARCELlOS, Ana Paula de. A eficácia Jurídica dos Princípios Constitucionais. Rio de Janeiro: Renovar, 2002.

BRASIL. Constituição da República Federativa do Brasil. Disponível em: 
http://.planalto.gov.br/ccivil_03/constituicao/constitui\%C3\%A7ao. htm. Acessado em: 22 de fev. de 2013.

CAMBI, Eduardo. Neoconstitucionalismo e neoprocessualismo: Direitos fundamentais, políticas públicas e protagonismo judiciário. São Paulo: Revista dos Tribunais, 2009.

CANOTILHO, José Joaquim Gomes. Direito constitucional e teoria da constituição. 3 ed. Coimbra: Almedina, 1999.

Direito Constitucional e Teoria da Constituição. 4 ed. Coimbra: Almedina, 2001.

KRELL, Andreas J. Direitos Sociais e Controle Judicial no Brasil e na Alemanha: os descaminhos de um direito constitucional “comparado”. Porto Alegre: Sergio Antônio Fabris Editor, 2002.

LENZA, Pedro. Direito Constitucional Esquematizado. 13 ed. São Paulo: Saraiva, 2009.

MEIRELLES, Hely Lopes. Direito Administrativo Brasileiro. 29 ed. São Paulo: Malheiros Editores, 2004.

MORAES, Alexandre de. Direito Constitucional Administrativo. 4 ed. São Paulo: Atlas, 2007.

OLIVEIRA, Régis Fernandes de. Curso de Direito Financeiro. São Paulo: Revista dos Tribunais, 2006.

ROCHA, Carmen Lúcia Antunes. O mínimo existencial e o princípio da reserva do possível. Belo Horizonte: Del Rey, 2005.

SARLET, Ingo Wolfgang. A eficácia dos direitos fundamentais. 2 ed. Porto Alegre: Livraria do Advogado, 2001. 